\title{
Significance of cytoplasmic expression of telomerase reverse transcriptase in patients with hepatocellular carcinoma undergoing liver resection
}

\author{
YUSUKE NISHI, TAKU AOKI, TAKAYUKI SHIMIZU, SHUN SATO, \\ TAKATSUGU MATSUMOTO, TAKAYUKI SHIRAKI, YUHKI SAKURAOKA, \\ SHOZO MORI, YUKIHIRO ISO, MITSURU ISHIZUKA and KEIICHI KUBOTA
}

Second Department of Surgery, Dokkyo Medical University, Mibu, Tochigi 321-0293, Japan

Received April 26, 2021; Accepted July 13, 2021

DOI: $10.3892 / \mathrm{mco} .2021 .2406$

\begin{abstract}
Telomerase reverse transcriptase (TERT) is reportedly expressed in various types of cancer. However, to the best of our knowledge, the significance of subcellular expression of TERT in hepatocellular carcinoma (HCC) has not been evaluated in detail. The present study evaluated TERT expression in resected HCC tumor tissues using immunohistochemistry. TERT expression was assessed in both the cytoplasm and the nucleus of HCC cells. The associations between TERT expression and clinical characteristics, including expression levels of DNA-dependent protein kinase catalytic unit (DNA-PKcs) and 8-hydroxyganosine (8-OHdG), were investigated. Among the $135 \mathrm{HCCs}$, TERT expression was positive only in the cytoplasm in 86 tumors (63.7\%), was positive only in the nucleus in 3 tumors $(2.2 \%)$, was positive in both the cytoplasm and the nucleus in 5 tumors $(3.7 \%)$ and was negative in 41 tumors (30.4\%). Similar results were confirmed using another antibody for TERT. Cytoplasmic TERT expression was markedly associated with hepatitis B surface antigen, poor tumor differentiation, and expression levels of DNA-PKcs and 8-OHdG. However, TERT expression in the cytoplasm or in the nucleus was not significantly associated with the overall or recurrence-free survival periods.
\end{abstract}

Correspondence to: Professor Taku Aoki, Second Department of Surgery, Dokkyo Medical University, 880 Kitakobayashi, Mibu, Tochigi 321-0293, Japan

E-mail: aoki-2su@dokkyomed.ac.jp

Abbreviations: AFP, $\alpha$-fetoprotein; DNA-PKcs, DNA-protein kinase catalytic subunit; 8-OHdG, 8-hydroxyganosine; HBsAg, hepatitis B surface antigen; HCC, hepatocellular carcinoma; HCVAb, anti-hepatitis C virus antibody; OS, overall survival; PIVKA-II, protein induced by vitamin $\mathrm{K}$ antagonist II; RFS, recurrence-free survival; TERT, telomerase reverse transcriptase; TNM stage, tumor-node-metastasis stage

Key words: HCC, liver resection, immunohistochemistry, TERT, intracellular distribution
In conclusion, TERT was mainly expressed in the cytoplasm of HCC tissues. Cytoplasmic TERT expression was closely associated with hepatitis B virus-related HCC and DNA-PKcs expression, as well as oxidative stress.

\section{Introduction}

Hepatocellular carcinoma (HCC) is the most common primary liver cancer and the third leading cause of cancer-related death worldwide (1). The incidence and mortality of HCC are reportedly increasing in North America and several European regions and decreasing in traditionally high-risk regions, including Asian countries (2). Nevertheless, the prevalence of HCC remains a critical global health issue (3).

Telomerase reverse transcriptase (TERT) is the catalytic protein subunit of telomerase and is responsible for maintaining chromosomal integrity and genomic stability through the addition of telomeres to the ends of chromosomes (4). In somatic cells, telomere loss occurs during each round of cell division, resulting in cellular aging (5). In contrast, telomerase is reactivated to prevent critical telomere shortening in cancer cells, thereby enabling cancer cells to acquire replicative immortality (6). Promoter mutations lead to an enhancement of TERT transcription and the acquisition of immortality in cancer cells.

Telomere shortening and reactivation of telomerase are described in a broad range of human cancers, including liver cancer $(7,8)$. Telomerase reactivation is associated with the alteration of transcriptional regulators of the TERT promotor in cancer, TERT promotor mutations or rearrangements and DNA copy number amplifications (9). It has been reported that reactivation of the telomerase enzymes was shown in more than $80 \%$ of HCCs, and TERT promotor somatic mutations was found in $59 \%$ of the HCCs $(8,9)$.

Regarding the relationship between liver disease and TERT promoter mutation of HCC, the mechanisms of the mutation have been reported in $\mathrm{HBV}$ - and $\mathrm{HCV}$-related HCC (9). In HBV related HCC, HBV directly integrates to TERT promoter region and activated TERT transcription (10). On the other hand, TERT promoter mutation of HCV-related $\mathrm{HCC}$ is more frequent compared as that of HBV (10). Although 
$\mathrm{HCV}$ is not able to integrate into host genome unlike HBV, it is considered that the core proteins of HCV directly affect TERT promoter (11). However, the intensity of TERT expression in HCC was not differed by TERT promoter mutation (12). It is skeptical whether TERT expression is associated with the outcome of HCC patients.

Actually, a few reports have shown the relationship between the outcome of HCC patients and the intercellular distribution of TERT protein expression. The TERT protein has been reported to be mainly distributed in the nuclei of glioblastoma cells, renal cell carcinoma cells, and lung cancer, oral cancer, colorectal cancer, and thyroid cancer cells (13-18). Conversely, two previous studies have shown that TERT protein is mainly distributed in the cytoplasm of HCC tumor cells $(12,19)$. Since telomeres are present in the nucleus, the predominant distribution of TERT in the cytoplasm of HCC tumor cells is difficult to understand. Additionally, the means by which the intracellular TERT distribution affects the clinical characteristics and outcomes of HCC patients undergoing surgery remains unknown.

In this study, we performed immunohistochemistry using two types of antibodies for TERT and evaluated TERT expression in resected HCC tumor tissues. We confirmed the significant of cytoplasmic expression of TERT in HCC cells from patients who had undergone liver resection. Additionally, we investigated the relationship between the intracellular distribution of TERT in HCC tumor tissues and the expression of DNA-protein kinase catalytic subunit (DNA-PKcs), which our group previously reported as a novel predictor in HCC patients (20), as well as expression of 8-hydroxyganosine (8-OHdG), a surrogate of oxidative stress and DNA damage.

\section{Materials and methods}

Patients. This study was conducted with the approval of the Ethical Review Board of the Dokkyo Medical University Hospital (ID number: 28110), in compliance with the Ethical Guidelines for Clinical Research published by the Ministry of Health, Labor and Welfare, Japan. We provided the enrolled patients with the opportunity to opt out on our website (www2. dokkyomed.ac.jp/dep-m/surg2/pg334.html).

From January 2012 to October 2019, 455 liver resections were performed for HCC at the Second Department of Surgery, Dokkyo Medical University Hospital. Among these, 135 HCC patients with good-quality pathological samples were retrospectively enrolled in this study. The 135 patients included 103 males and 32 females, with a mean age \pm standard deviation of 68.6 \pm 9.0 years (range, 33-91 years). Thirty-seven patients were positive for hepatitis B surface antigen (HBsAg), 37 were positive for anti-hepatitis $\mathrm{C}$ virus antibody (HCVAb), 2 were positive for both $\mathrm{HBsAg}$ and $\mathrm{HCVAb}$, and 59 were negative for both.

Routine postoperative surveillance was usually performed every 3 months for patients who had undergone surgery. To detect HCC recurrences, the levels of tumor markers, including $\alpha$-fetoprotein (AFP) and protein induced by vitamin $\mathrm{K}$ antagonist II (PIVKA-II), were measured every 3 months after surgery. In addition, helical dynamic computed tomography was also performed every 6 months or when the tumor marker levels exceeded the normal range. Beginning at 3 years after the surgery, the HDCT interval was extended from 6 to 12 months. HDCT was performed whenever an elevation in the tumor marker levels was observed.

Primary antibody and immunohistochemistry. The methods of immunohistochemistry have been described previously (20). In brief, resected liver specimens were fixed in $10 \% \mathrm{v} / \mathrm{v}$ formalin, cut into blocks, and embedded in paraffin. The blocks were sliced into $4 \mu \mathrm{m}$-thick sections and stained with hematoxylin and eosin or used for immunohistochemical analysis. The TERT antibodies used for the analysis were a rabbit monoclonal antibody (ab32020; Abcam) and a mouse monoclonal antibody (sc-393013; Santa Cruz Biotechnology, Inc.). The antibody for DNA-PKcs used was a mouse monoclonal antibody (\#12311; Cell Signaling Technology, Inc). The $8-\mathrm{OHdG}$ antibody used for the analysis were a mouse monoclonal antibody (ab48508; Abcam). The sections were subjected to dewaxing, heat-induced epitope retrieval with citrate buffer, antibody incubation (TERT: dilution 1:50, 15 min; DNA-PKcs: Dilution 1:30, $45 \mathrm{~min}$; 8-OHdG: Dilution 1:100, $45 \mathrm{~min}$ ) and counterstaining on a BOND Max immunostainer using Bond Epitope Retrieval Solution 2 (pH-9.0, $20 \mathrm{~min}$ ) for TERT and DNA-PKcs, Bond Epitope Retrieval Solution 1 ( $\mathrm{pH}-6.0,10 \mathrm{~min}$ ) for 8-OHdG and the Bond Polymer Refine Detection kit (Menarini). The TERT expression was judged as positive when staining of the cytoplasm or the nucleus was observed in more than $30 \%$ of the tumor cells. The DNA-PKcs expression was judged as positive when staining of the nuclei was observed at tumor edge in more than $30 \%$ of the tumor cells. The $8-\mathrm{OHdG}$ expression was judged as positive when staining of the nuclei was observed in more than $30 \%$ of the tumor cells.

Statistical analysis. The correlation between the intercellular distribution of TERT expression and various clinical and pathological characteristics were analyzed using the chi-square test, Fisher's exact test, or Mann-Whitney U test, as appropriate. The following clinical and pathological characteristics were examined: Patient age (years), sex (male/female), HBsAg (positive/negative), HCVAb (positive/negative), Child-Pugh class (B/A), liver cirrhosis (yes/no), poor tumor differentiation (yes/no), serum levels of AFP (ng/ml) and PIVKA-II (mAU/ml), size of the largest tumor nodule $(\mathrm{cm})$, tumor number $(\geq 2 / 1)$, portal vein invasion (yes/no), tumor-node-metastasis (TNM) stage in accordance with the Union for International Cancer Control (UICC) classification, 8th edition (21), and DNA-PKcs expression (positive/negative). The Kaplan-Meier method and the log-rank test were performed to investigate the relationship between TERT expression and the postoperative outcomes of HCC patients. All the statistical analyses were performed using IBM SPSS statistics version 25.0 software for Windows (IBM Co.). $\mathrm{P}<0.05$ was considered to indicate a statistically significant difference.

\section{Results}

TERT expression in HCC. First, 135 HCCs were stained using a rabbit monoclonal TERT antibody. TERT expression was positive only in the cytoplasm in 86 tumors $(63.7 \%)$, was positive only in the nucleus in 3 tumors $(2.2 \%)$, was positive in both the 


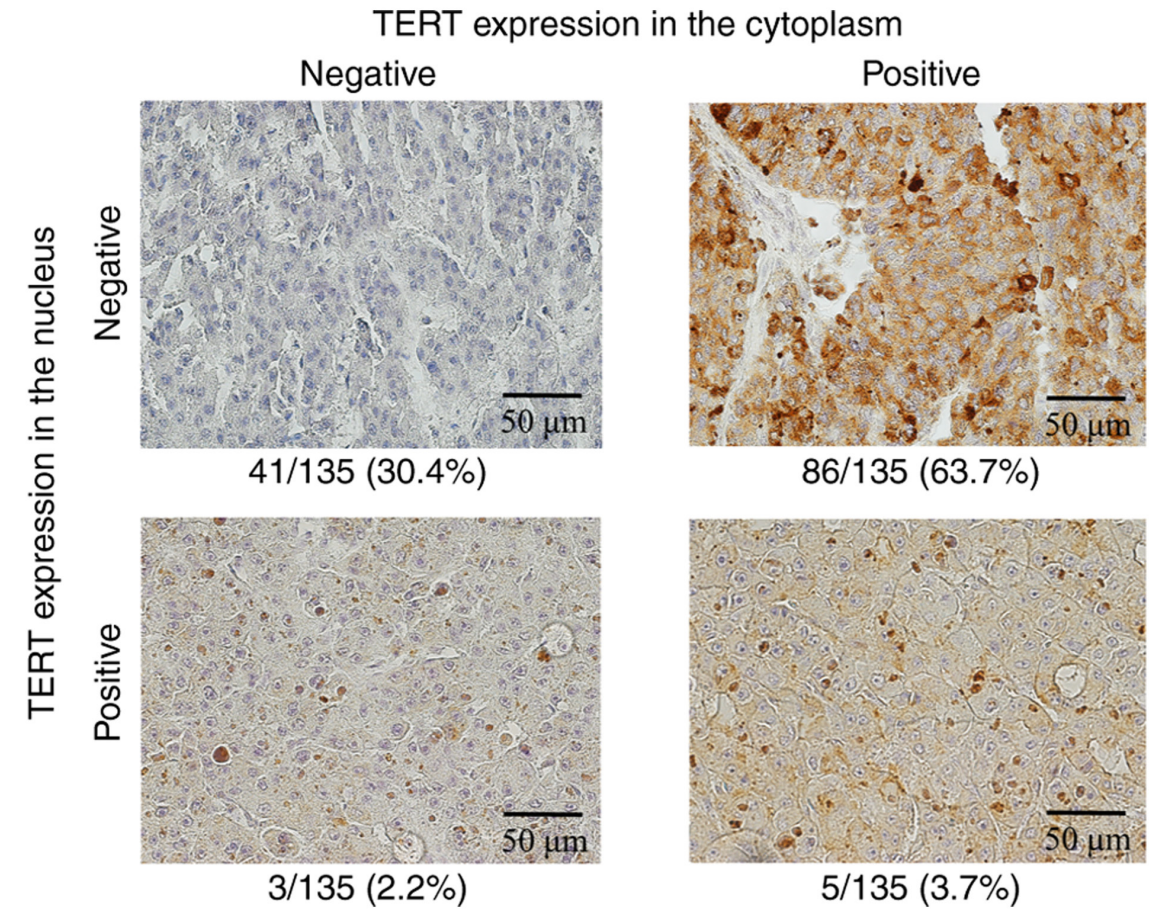

Figure 1. Immunohistochemistry of HCC tumors with rabbit monoclonal antibody. TERT expression in the cytoplasm and in the nucleus of HCC tissues. Scale bar, $50 \mu \mathrm{m}$. HCC, hepatocellular carcinoma; TERT, telomerase reverse transcriptase.

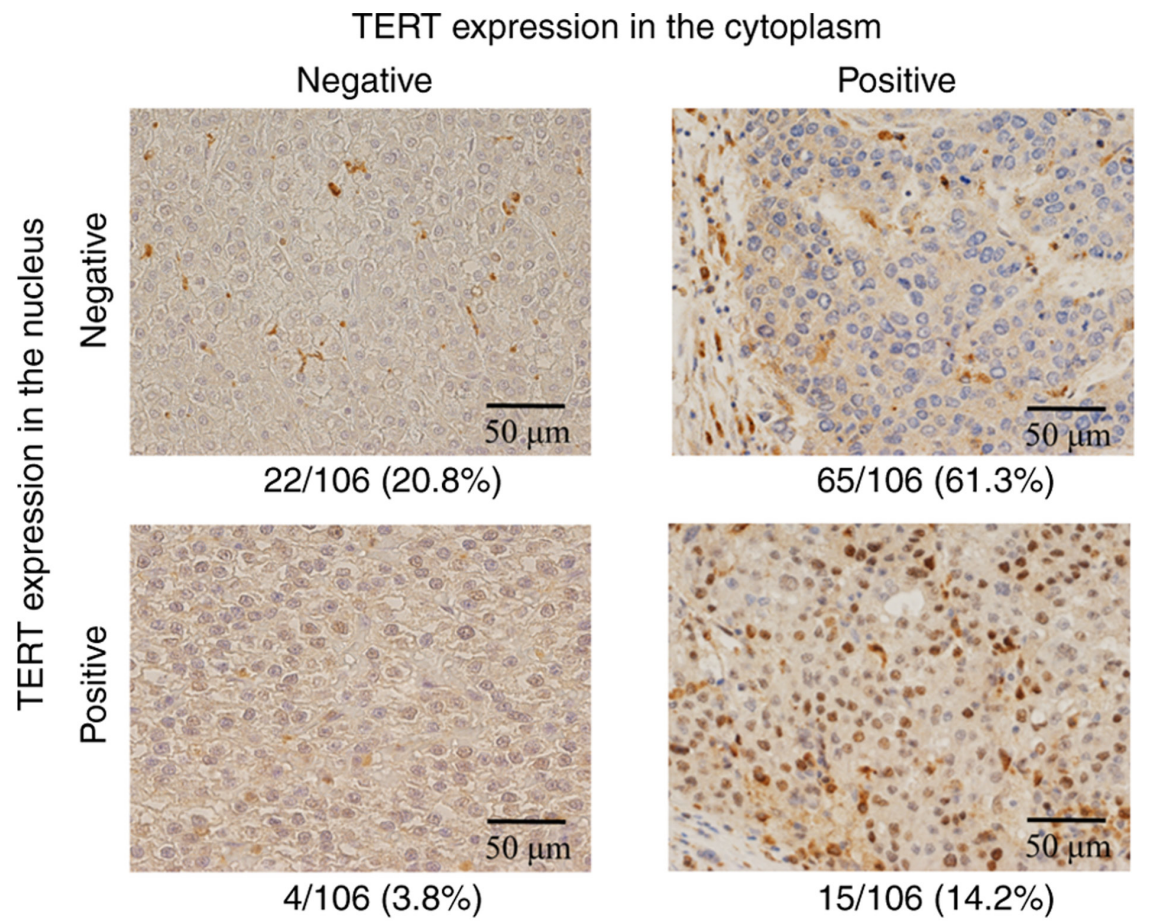

Figure 2. Immunohistochemistry of hepatocellular carcinoma tumors with a mouse monoclonal antibody. Scale bar, $50 \mu \mathrm{m}$. TERT, telomerase reverse transcriptase.

cytoplasm and the nucleus in 5 tumors (3.7\%), and was negative in 41 tumors (30.4\%), respectively (Fig. 1). In total, TERT expression in the HCC tissues was positive in the cytoplasm in 91 tumors $(67.4 \%)$ and was positive in the nucleus in 8 tumors $(5.9 \%)$.

In the tumors with TERT expression in both the cytoplasm and the nucleus, most tumor cells were positive in both the cytoplasm and the nucleus, and the proportion of the tumor cells which were positive only in the cytoplasm or in the nucleus was low.

Results of repeated IHC using another primary antibody for TERT. Because the intracellular distribution of TERT in HCC tissues apparently differed from that found in other malignancies, repeated immunohistochemistry using a mouse monoclonal antibody was performed for 85 HCCs (Fig. 2). As 
Table I. Results of immunohistochemistry using two types of primary antibodies for TERT.

\begin{tabular}{|c|c|c|c|c|}
\hline \multirow[b]{2}{*}{ Rabbit mAb } & \multicolumn{4}{|c|}{ Mouse mAb } \\
\hline & $\begin{array}{c}\text { Cytoplasm } \\
(-) / \text { nucleus (-), n }\end{array}$ & $\begin{array}{c}\text { Cytoplasm } \\
(+) / \text { nucleus (-), n }\end{array}$ & $\begin{array}{c}\text { Cytoplasm } \\
(-) / \text { nucleus }(+), n\end{array}$ & $\begin{array}{c}\text { Cytoplasm } \\
(+) / \text { nucleus }(+), \mathrm{n}\end{array}$ \\
\hline Cytoplasm (-)/nucleus (-) & 17 & 10 & 1 & 4 \\
\hline Cytoplasm (+)/nucleus (-) & 3 & 39 & 1 & 4 \\
\hline Cytoplasm (-)/nucleus (+) & 0 & 1 & 0 & 1 \\
\hline Cytoplasm (+)/nucleus (+) & 0 & 1 & 0 & 3 \\
\hline
\end{tabular}

Mouse mAb, mouse monoclonal primary TERT antibody; Rabbit mAb, rabbit monoclonal primary TERT antibody; TERT, telomerase reverse transcriptase.

shown in Table I, the results of the two immunohistochemical series were consistent for 69 of the HCC tumors $(81.1 \%, 69 / 85$, expression shown by gray-colored cells). The results of the two types of TERT antibodies were shown to be significantly consistent $(\mathrm{P}<0.001)$.

Correlation between TERT expression in the cytoplasm and clinical and pathological characteristics. Table II shows the clinical and pathological characteristics of the patients stratified according to TERT expression in the cytoplasm of the HCC tissues. The analyses revealed significant intergroup differences in the HBsAg (positive/negative), poor tumor differentiation (yes/no), DNA-PKcs expression (positive/negative), and 8-OHdG expression (positive/negative) (Fig. 3).

Correlation between tumor TERT expression in the nucleus and clinical and pathological characteristics. Table III shows the clinical and pathological characteristics of the patients stratified according to TERT expression in the nucleus of the HCC tissues. Analyses revealed no significant intergroup differences in the clinical and pathological characteristics. The clinical and pathological characteristics of the patients without TERT expression in the cytoplasm or in the nucleus were also investigated, and the inter-group analysis showed significant differences in liver cirrhosis (yes/no/NA) and DNA-PKcs expression (positive/negative) (Table SI).

Correlation between DNA-PKcs and 8-OHdG expressions. The examination of the association between DNA-PKcs and $8-\mathrm{OHdG}$ expressions showed no significant relationship between the two factors $(\mathrm{P}=0.667)$.

Relationship between intracellular distribution of TERT expression and postoperative outcomes. The median follow-up period was 1,089 days (range, 12-2,562 days). During the observation period, 54 patients died; the cause of death was cancer recurrence in 35 patients; liver failure in 9 patients; pneumonia in 4 patients; renal failure, sepsis, ureteral cancer, gastrointestinal perforation in one patient each; and unknown in 2 patients. TERT expression in the cytoplasm or in the nucleus was not significantly associated with the overall and recurrence-free survival periods (Fig. 4).

\section{Discussion}

The present results showed that TERT was mainly expressed in the cytoplasm of HCC tumor tissues. The present results were confirmed using another TERT antibody. These findings suggest that TERT protein might be transferred from the nucleus to the cytoplasm of HCC tumor cells, since TERT protein is originally expressed in the nucleus (13-18). Overall, $67.4 \%(91 / 135)$ of the HCC tumors had positive TERT expression in the cytoplasm, and TERT expression in the nuclei was negative in most of the cases. The previous reports have shown that over $90 \%$ of the tumor cells had positive TERT expression in their cytoplasm, and about half of the cells had positive TERT expression in their nucleus $(12,19)$. The differences in the positive ratios between our results and those reported in the previous articles may be ascribed to the difference in the patient cohort and the difference in the positive decision criteria.

As mentioned above, the canonical function of TERT is to maintain telomere length and genomic stability at telomeres. On the other hand, previous reports have suggested that telomerase show various non-canonical functions in the nucleus, cytoplasm, and mitochondria. These functions include activation of intracellular signaling pathways associated with inflammation, epithelial to mesenchymal transition and tumor cell invasion and metastasis, especially interaction with Wnt/ $\beta$-catenin signaling pathway as well as NF- $\kappa$ B signaling pathway (22-24). In addition, mitochondrial TERT has various non-canonical functions such as protection against reactive oxygen species and influence on mitochondrial DNA damage and mitochondrial integrity $(22,23)$. Our present results may suggest that TERT exhibit its non-canonical function in the cytoplasm, contributing to tumor development.

Interestingly, oxidative stress reportedly induces TERT translocation from the nucleus to the cytoplasm, and translocation from the nucleus to the mitochondria $(22,23,25)$. Previously, we reported that NRF2, a transcription factor that responds to oxidative stress, frequently accumulates in the nucleus in approximately $70 \%$ of HCC tumors (26). These observations support the speculation that TERT is transferred from the nucleus to the cytoplasm in HCC tumor cells as a result of oxidative stress. In the present study, we investigated the nuclear expression of $8-\mathrm{OHdG}$, a surrogate of oxidative 
Table II. Association between clinical characteristics and cytoplasmic TERT expression in patients with hepatocellular carcinoma undergoing surgery.

\begin{tabular}{|c|c|c|c|}
\hline Variable & Cytoplasmic TERT (-) $(\mathrm{n}=44)$ & Cytoplasmic TERT (+) (n=91) & P-value \\
\hline Age $^{\mathrm{a}}$, years & $71(67-75)$ & $69(63-75)$ & 0.279 \\
\hline $\operatorname{Sex}^{\mathrm{b}}, \mathrm{n}$ & & & 0.805 \\
\hline Male & 33 & 70 & \\
\hline Female & 11 & 21 & \\
\hline HBs antigen positive ${ }^{\mathrm{b}}, \mathrm{n}$ & & & 0.007 \\
\hline Yes & 6 & 33 & \\
\hline No & 38 & 58 & \\
\hline $\mathrm{HCV}$ antibody positive ${ }^{\mathrm{b}}, \mathrm{n}$ & & & 0.354 \\
\hline Yes & 15 & 24 & \\
\hline No & 29 & 67 & \\
\hline Child-Pugh class ${ }^{\mathrm{c}}, \mathrm{n}$ & & & 0.576 \\
\hline A & 36 & 77 & \\
\hline $\mathrm{B}$ & 8 & 13 & \\
\hline Not available & 0 & 1 & \\
\hline Liver cirrhosis $^{\mathrm{c}}, \mathrm{n}$ & & & 0.101 \\
\hline Yes & 12 & 38 & \\
\hline No & 31 & 51 & \\
\hline Not available & 1 & 2 & \\
\hline Poor tumor differentiation ${ }^{c}, n$ & & & 0.043 \\
\hline Yes & 3 & 19 & \\
\hline No & 40 & 72 & \\
\hline Not available & 1 & 0 & \\
\hline $\mathrm{AFP}^{\mathrm{a}}, \mathrm{ng} / \mathrm{ml}$ & $4(3-58)$ & $10(4-92)$ & 0.849 \\
\hline PIVKA-II ${ }^{\mathrm{a}}, \mathrm{mAU} / \mathrm{ml}$ & $38(18-146)$ & $79(27-587)$ & 0.239 \\
\hline Size of largest tumor nodule ${ }^{\mathrm{a}}, \mathrm{cm}$ & $3.2(2.2-5.3)$ & $3.0(2.0-5.6)$ & 0.135 \\
\hline Tumor number ${ }^{\mathrm{b}}, \mathrm{n}$ & & & 0.973 \\
\hline$\geq 2$ & 11 & 23 & \\
\hline 1 & 33 & 67 & \\
\hline Portal vein invasion ${ }^{\mathrm{b}}, \mathrm{n}$ & & & 0.417 \\
\hline Yes & 13 & 21 & \\
\hline No & 31 & 70 & \\
\hline TNM $_{\text {stage }}{ }^{\mathrm{b}}, \mathrm{n}$ & & & 0.741 \\
\hline $\mathrm{I}$ & 21 & 42 & \\
\hline II & 13 & 23 & \\
\hline III & 10 & 26 & \\
\hline DNA-PKcs ${ }^{\mathrm{b}}, \mathrm{n}$ & & & 0.042 \\
\hline Positive & 16 & 37 & \\
\hline Negative & 14 & 12 & \\
\hline Not available & 14 & 42 & \\
\hline
\end{tabular}

Associations were examined using the a Mann-Whitney U test, ${ }^{b} \chi^{2}$ test and ${ }^{c}$ Fisher's exact test, as appropriate. Continuous data expressed as the median (range). AFP, $\alpha$-fetoprotein; PIVKA-II, protein induced by vitamin K antagonist II; HBs, hepatitis B surface; HCV, hepatitis C virus; TNM, tumor-node-metastasis; DNA-PKcs, DNA-dependent protein kinase catalytic subunit; TERT, telomerase reverse transcriptase.

stress and DNA damage, in 85 HCC specimens. The results clearly showed the positive relationship between cytoplasmic TERT expression and nuclear $8-\mathrm{OHdG}$ expression. The present results also support the hypothesis that oxidative stress is involved in the translocation of TERT. In detail, $\mathrm{H}_{2} \mathrm{O}_{2}$-induced nuclear export of TERT is reportedly triggered via Src kinase family-dependent phosphorylation of tyrosine 707 (25). We also examined the relationship between the DNA-PKcs and 8-OHdG expressions, but the result was insignificant. We have no clear explanation for the result; we speculate that 


\section{DNA-PKcs negative}

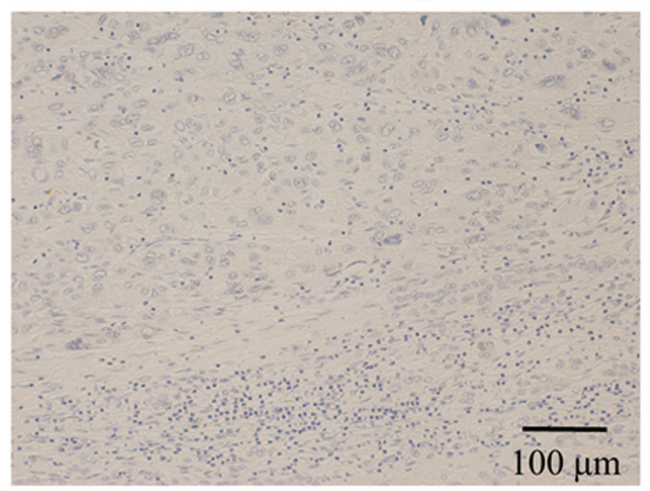

8-OHdG negative

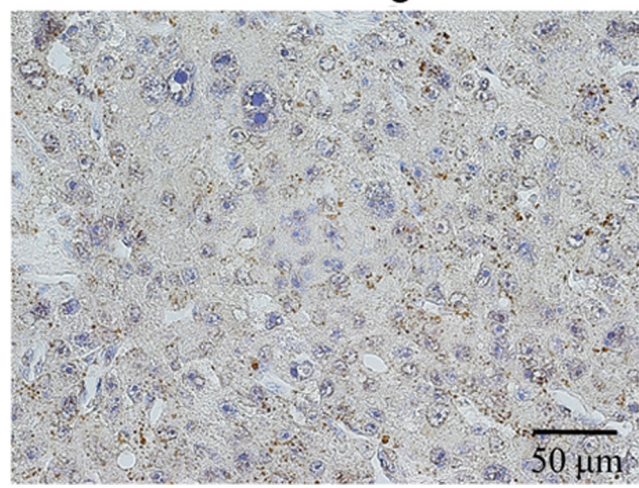

DNA-PKcs positive

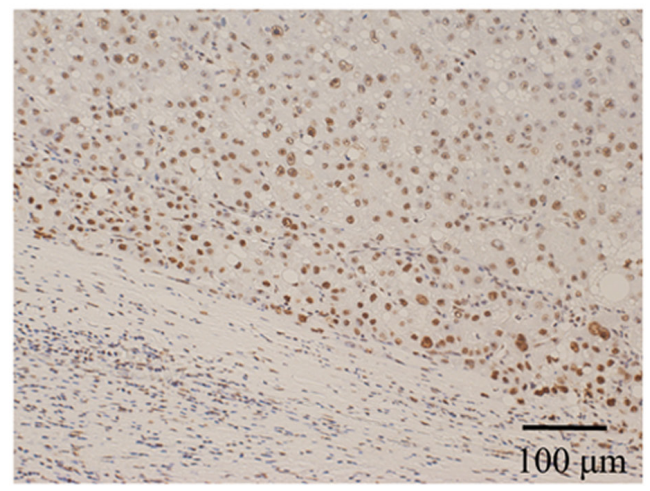

8-OHdG positive

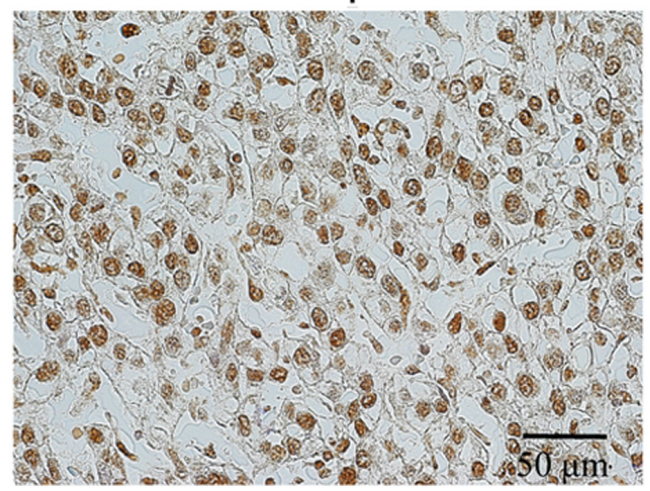

Figure 3. Immunohistochemistry of HCC tumors. DNA-PKcs (scale bar, $100 \mu \mathrm{m}$ ) and 8-OHdG (scale bar, $50 \mu \mathrm{m}$ ) expression in HCC. 8-OHdG, 8-hydroxyganosine; DNA-PKcs, DNA-protein kinase catalytic subunit; HCC, hepatocellular carcinoma.

this negative result may be ascribed to the small number of samples.

Our results showed that cytoplasmic TERT expression was significantly associated with HBsAg. Previous studies have revealed a relationship between HBV infection and TERT expression $(10,12,19)$. TERT overexpression in HBV-associated HCC tumors has been ascribed to TERT promoter mutations or HBV integration into the genetic locus of TERT $(10,12,19)$. However, the relationship between HBV infection and cytoplasmic TERT expression remains unclear. Further investigation is needed to clarify the relationship between the HBV infection and altered subcellular expression of TERT.

Our results showed that cytoplasmic TERT expression was significantly associated with DNA-PKcs expression. DNA-PKcs is reportedly a host protein of HBV-RNA and is significantly associated with HBV infection and the postoperative outcome of HCC patients undergoing surgery $(20,27)$. Because HBsAg and HBV-RNA are transcribed by covalently closed circular DNA (cccDNA), TERT and DNA-PKcs expression in HBV-related HCC might be influenced by the presence of cccDNA. However, the current anti-viral drugs for HBV are unable to treat cccDNA; consequently, the development of treatments for cccDNA is needed to improve the outcomes of patients with HBV infection.

Although our results showed that cytoplasmic TERT expression was significantly associated with poor tumor differentiation, a previous study reported thathigher cytoplasmic
TERT expression was associated with well-differentiated HCC tumors (19). On the other hand, another report showed that telomerase activation was significantly related to the poor tumor differentiation of HCC tumors (28). In thyroid cancer, TERT promoter mutation was frequently observed in poorly differentiated tumors (29). The role of TERT is not only the acquisition of tumor immortality, but also interactions with several oncogenic pathways such as the Wnt/ $\beta$-catenin signal pathway and p53 suppression $(30,31)$. Although the relationship between cytoplasmic TERT expression and tumor differentiation remains unclear, the present evidence suggests that cytoplasmic TERT expression might affect the tumor dedifferentiation of malignancies, including HCC.

Previous studies have reported that TERT promoter mutation and TERT expression are associated with unfavorable outcomes in HCC patients $(10,12,19)$. On the other hand, our results showed that TERT expression in the cytoplasm or in the nucleus was not closely associated with the postoperative outcomes of HCC patients. Our results suggested that TERT expression is associated with neither tumor progression nor metastasis. Because the TERT mutation already occurs in premalignant liver tumor cells $(9,12)$, the role of TERT in HCC probably does not involve tumor progression, but rather involves liver carcinogenesis and tumor dedifferentiation. Recently, Ako et al (32) evaluated the human TERT promotor mutations detected in the serum of the HCC patients using modified droplet digital polymerase chain reaction and found that positive TERT promotor mutation was significantly 
Table III. Association between clinical characteristics and nucleus TERT expression in patients with hepatocellular carcinoma undergoing surgery.

\begin{tabular}{|c|c|c|c|}
\hline Variable & Nucleus TERT (-) $(\mathrm{n}=127)$ & Nucleus TERT $(+)(\mathrm{n}=8)$ & P-value \\
\hline Age $^{\mathrm{a}}$, years & $70(65-75)$ & $70(66-72)$ & 0.733 \\
\hline $\operatorname{Sex}^{\mathrm{b}}, \mathrm{n}$ & & & 0.358 \\
\hline Male & 96 & 7 & \\
\hline Female & 31 & 1 & \\
\hline HBs antigen positive ${ }^{b}, n$ & & & 0.490 \\
\hline Yes & 37 & 2 & \\
\hline No & 90 & 6 & \\
\hline $\mathrm{HCV}$ antibody positive ${ }^{\mathrm{b}}, \mathrm{n}$ & & & 0.207 \\
\hline Yes & 38 & 1 & \\
\hline No & 89 & 7 & \\
\hline Child-Pugh class ${ }^{\mathrm{c}}, \mathrm{n}$ & & & 0.573 \\
\hline A & 106 & 7 & \\
\hline $\mathrm{B}$ & 20 & 1 & \\
\hline Not available & 1 & 0 & \\
\hline 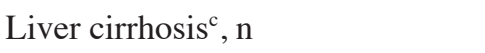 & & & 0.354 \\
\hline Yes & 46 & 4 & \\
\hline No & 79 & 3 & \\
\hline Not available & 2 & 1 & \\
\hline Poor tumor differentiation $^{c}, \mathrm{n}$ & & & 0.453 \\
\hline Yes & 20 & 2 & \\
\hline No & 106 & 6 & \\
\hline Not available & 1 & 0 & \\
\hline $\mathrm{AFP}^{\mathrm{a}}, \mathrm{ng} / \mathrm{ml}$ & $7(3-74)$ & $3(2-18)$ & 0.103 \\
\hline PIVKA-II ${ }^{\mathrm{a}}, \mathrm{mAU} / \mathrm{ml}$ & $71(23-444)$ & $41(22-80)$ & 0.187 \\
\hline Size of largest tumor nodule ${ }^{\mathrm{a}}, \mathrm{cm}$ & $3.1(2.1-5.9)$ & $2.9(1.9-4.2)$ & 0.363 \\
\hline Tumor number ${ }^{\mathrm{b}}, \mathrm{n}$ & & & 0.287 \\
\hline$\geq 2$ & 33 & 1 & \\
\hline 1 & 94 & 7 & \\
\hline Portal vein invasion ${ }^{\mathrm{b}}, \mathrm{n}$ & & & 0.595 \\
\hline Yes & 33 & 1 & \\
\hline No & 94 & 7 & \\
\hline 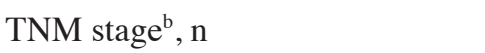 & & & 0.549 \\
\hline I & 58 & 5 & \\
\hline II & 33 & 3 & \\
\hline III & 35 & 1 & \\
\hline DNA-PKcs ${ }^{b}, n$ & & & 0.251 \\
\hline Positive & 50 & 3 & \\
\hline Negative & 25 & 1 & \\
\hline Not available & 52 & 4 & \\
\hline
\end{tabular}

Continuous data are presented as the median (range). Associations were examined using ${ }^{\mathrm{a}} \mathrm{Mann}-$ Whitney U test, ${ }^{\mathrm{b}} \chi^{2}$ test and ${ }^{\mathrm{c}} \mathrm{Fisher}$ 's exact test, as appropriate. AFP, $\alpha$-fetoprotein; PIVKA-II, protein induced by vitamin K antagonist II; HBs, hepatitis B surface; HCV, hepatitis C virus; TNM, tumor-node-metastasis; DNA-PKcs, DNA-dependent protein kinase catalytic subunit.

associated with shorter recurrence-free survival period after surgery. Clinical impact of TERT gene promotor mutation as well as overexpression of TERT protein on tumor biology and patient outcomes is to be clarified by various aspects of investigations.
A potential limitation of the present study was that this was a retrospective study performed at a single institution and with a small cohort of patients. Therefore, we could not exclude the influence of bias provided by the retrospective design of the study, and this may explain the inconsistencies with previous reports. 
A

Cytoplasmic TERT \& OS $\quad P=0.157$

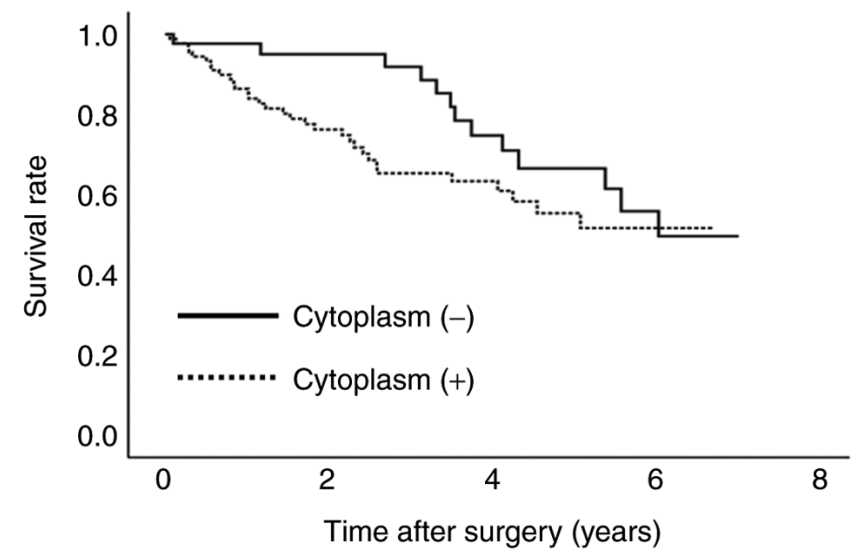

C Nucleus TERT \& OS $P=0.383$

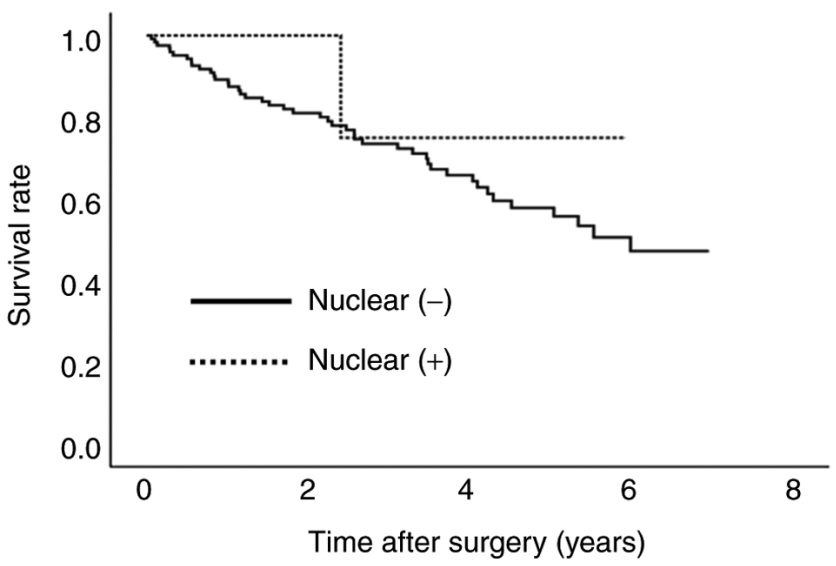

B

Cytoplasmic TERT \& RFS $P=0.864$

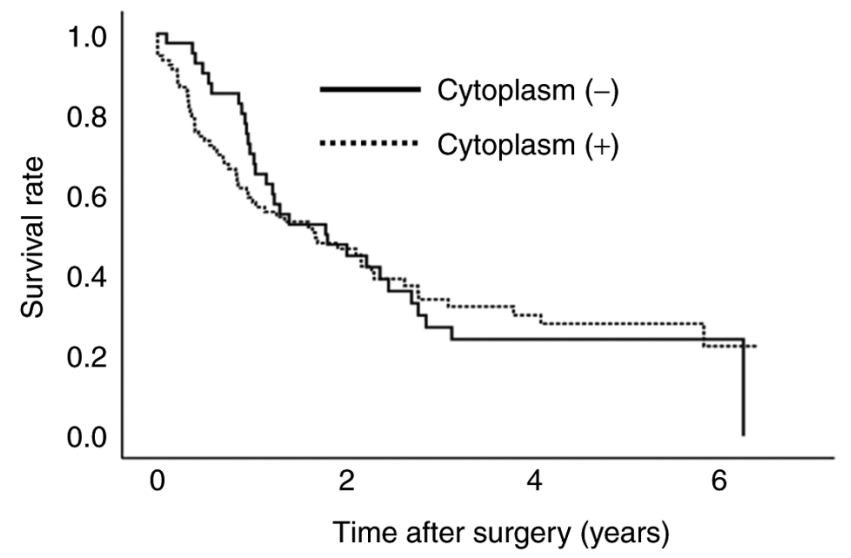

D Nucleus TERT \& RFS $P=0.799$

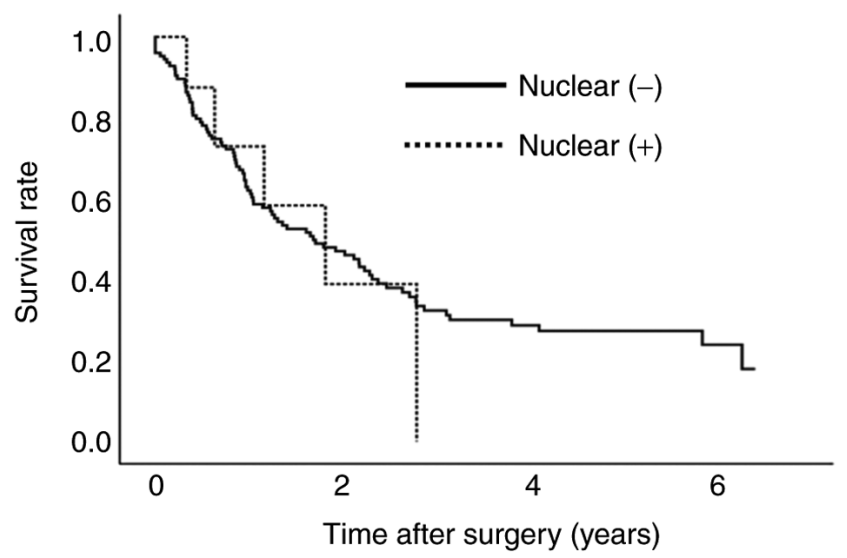

Figure 4. Relationship between TERT expression in the cytoplasm or in the nucleus and postoperative survival in patients with hepatocellular carcinoma undergoing liver resection. (A) TERT expression in the cytoplasm and OS. (B) TERT expression in the cytoplasm and RFS. (C) TERT expression in the nucleus and OS. (D) TERT expression in the nucleus TERT and RFS. The survival curves were generated using the Kaplan-Meier method and were compared using the log-rank test. OS, overall survival; RFS, recurrence-free survival; TERT, telomerase reverse transcriptase.

In conclusion, unlike its expression in other malignancies, TERT is mainly expressed in the cytoplasm of HCC tumor tissues. Cytoplasmic TERT expression was significantly associated with HBsAg, poor tumor differentiation, DNA-PKcs expression, and 8-OHdG expression.

\section{Acknowledgements}

The authors would like to thank Professor Hajime Kuroda (Department of Pathology, Dokkyo Medical University, Mibu, Japan) for providing helpful comments and suggestions regarding the pathological evaluations.

\section{Funding}

This research was supported by the Research Program on Hepatitis from the Japan Agency for Medical Research and Development (AMED; grant no. JP18fk0210014).

\section{Availability of data and materials}

The datasets used and/or analyzed during the current study are available from the corresponding author on reasonable request.

\section{Authors' contributions}

TA conceived the study. YN, TShim and TA searched the published works. YN, TShim, TA, SS, TM, TShir, YS, SM, YI and KK performed liver resections and were involved in acquisition of data. YN, TShim, TA, and KK performed the data analyses and interpreted the data. TShim, TM and MI performed the statistical analyses. TA and TShim confirm the authenticity of all the raw data. YN wrote the first draft of the report. TA and KK performed critical review of the manuscript. All authors have read and approved the final manuscript.

\section{Ethics approval and consent to participate}

The present study was conducted with the approval of the Ethical Review Board of the Dokkyo Medical University Hospital (ID number: 28110; Mibu, Tochigi, Japan), in compliance with the Ethical Guidelines for Clinical Research published by the Ministry of Health, Labor and Welfare, Japan. We provided the enrolled patients with the opportunity to opt out on our website (www2.dokkyomed. ac.jp/dep-m/surg2/pg334.html). 


\section{Patient consent for publication}

Not applicable.

\section{Competing interests}

The authors declare that they have no competing interests.

\section{References}

1. Altekruse SF, Henley SJ, Cucinelli JE and McGlynn KA: Changing hepatocellular carcinoma incidence and liver cancer mortality rates in the United States. Am J Gastroenterol 109: 542-553, 2014.

2. Kulik L and El-Serag HB: Epidemiology and management of hepatocellular carcinoma. Gastroenterology 156: 477-491.e1, 2019.

3. Singal AG and El-Serag HB: Hepatocellular carcinoma from epidemiology to prevention: Translating knowledge into practice. Clin Gastroenterol Hepatol 13: 2140-2151, 2015.

4. Moyzis RK, Buckingham JM, Cram LS, Dani M, Deaven LL, Jones MD, Meyne J, Ratliff RL and Wu JR: A highly conserved repetitive DNA sequence, (TTAGGG)n, present at the telomeres of human chromosomes. Proc Natl Acad Sci USA 85: 6622-6626, 1988.

5. Blasco MA: Telomeres and human disease: Ageing, cancer and beyond. Nat Rev Genet 6: 611-622, 2005.

6. Hanahan D and Weinberg RA: Hallmarks of cancer: The next generation. Cell 144: 646-674, 2011.

7. Killela PJ, Reitman ZJ, Jiao Y, Bettegowda C, Agrawal N, Diaz LA Jr, Friedman AH, Friedman H, Gallia GL, Giovanella BC, et al: TERT promoter mutations occur frequently in gliomas and a subset of tumors derived from cells with low rates of self-renewal. Proc Natl Acad Sci USA 110: 6021-6026, 2013.

8. In der Stroth L, Tharehalli U, Günes C and Lechel A: Telomeres and telomerase in the development of liver cancer. Cancers (Basel) 12: 2048, 2020

9. Nault JC, Mallet M, Pilati C, Calderaro J, Bioulac-Sage P, Laurent C, Laurent A, Cherqui D, Balabaud C and Zucman-Rossi J: High frequency of telomerase reverse-transcriptase promoter somatic mutations in hepatocellular carcinoma and preneoplastic lesions. Nat Commun 4: 2218, 2013.

10. Kawai-Kitahata F, Asahina Y, Tanaka S, Kakinuma S, Murakawa M, Nitta S, Watanabe T, Otani S, Taniguchi M, Goto F, et al: Comprehensive analyses of mutations and hepatitis B virus integration in hepatocellular carcinoma with clinicopathological features. J Gastroenterol 51: 473-486, 2016.

11. Donaires FS, Scatena NF, Alves-Paiva RM, Podlevsky JD Logeswaran D, Santana BA, Teixeira AC, Chen JJ, Calado RT and Martinelli ALC: Telomere biology and telomerase mutations in cirrhotic patients with hepatocellular carcinoma. PLoS One 12: e0183287, 2017

12. Yang X, Guo X, Chen Y, Chen G, Ma Y, Huang K, Zhang Y, Zhao Q, Winkler CA, An P and Lyu J: Telomerase reverse transcriptase promoter mutations in hepatitis B virus-associated hepatocellular carcinoma. Oncotarget 7: 27838-27847, 2016.

13. Schjolberg AR, Clausen OP, Burum-Auensen E and De Angelis PM: Aneuploidy is associated with TP53 expression but not with BRCA1 or TERT expression in sporadic colorectal cancer. Anticancer Res 29: 4381-4387, 2009.

14. PalaniJ,Lakshminarayanan Vand KannanR:Immunohistochemical detection of human telomerase reverse transcriptase in oral cancer and pre-cancer. Indian J Dent Res 22: 362, 2011.

15. Qin Y, Chen W, Xiao Y, Yu W, Cai X, Dai M, Xu T, Huang W, Guo W, Deng W and Wu T: RFPL3 and CBP synergistically upregulate hTERT activity and promote Lung cancer growth. Oncotarget 6: 27130-27145, 2015.

16. Insilla AC, Proietti A, Borrelli N, Macerola E, Niccoli C, Vitti P, Miccoli $\mathrm{P}$ and Basolo F: TERT promoter mutations and their correlation with BRAF and RAS mutations in a consecutive cohort of 145 thyroid cancer cases. Oncol Lett 15: 2763-2770, 2018.
17. Trifunovic J, Prvanovic M, Jovanovic A, Dzamic Z, Lazic M, Ristanovic M, Radojevic-Skodric S and Basta-Jovanovic G: Immunohistochemical expression of proliferative markers in renal cell carcinoma. J BUON 23: 1103-1110, 2018.

18. Potharaju M, Mathavan A, Mangaleswaran B, Patil S, John R, Ghosh S, Kalavakonda C, Ghosh M and Verma RS: Clinicopathological analysis of HIF-1alpha and TERT on survival outcome in glioblastoma patients: A prospective, single institution study. J Cancer 10: 2397-2406, 2019.

19. Huang W, Zhou W, Li C, Yang Y, Shang YK, Chen C, Zhang J, Yao R, Wang P, Wen W, et al: Promoter mutations and cellular distribution of telomerase in non-clear cell and clear cell hepatocellular carcinoma. Oncotarget 8: 26288-26297, 2017.

20. Shimizu T, Aoki T, Mori S, Iso Y, Kato M, Ishizuka M and Kubota K: Tumor DNA-dependent protein kinase catalytic subunit expression is associated with hepatitis B surface antigen status and tumor progression in patients with hepatocellular carcinoma. Sci Rep 8: 15019, 2018.

21. James DB, Mary KG and Christian W (eds): TNM Classification of Malignant Tumors. 8th edition. Wiley Blackwell, Oxford, pp80-81, 2017.

22. Saretzki G: Extra-telomeric functions of human telomerase: Cancer, mitochondria and oxidative stress. Curr Pharm Des 20: 6386-6403, 2014

23. Thompson CAH and Wong JMY: Non-canonical functions of telomerase reverse transcriptase: Emerging roles and biological relevance. Curr Top Med Chem 20: 498-507, 2020.

24. Ghareghomi S, Ahmadian S, Zarghami N and Kahroba $\mathrm{H}$ : Fundamental insights into the interaction between telomerase/TERT and intracellular signaling pathways. Biochemie 181: 12-24, 2021.

25. Haendeler J, Hoffmann J, Brandes RP, Zeiher AM and Dimmeler S: Hydrogen peroxide triggers nuclear export of telomerase reverse transcriptase via Src kinase family-dependent phosphorylation of tyrosine 707. Mol Cell Biol 23: 4598-4610, 2003.

26. Shimizu T, Inoue $K$, Hachiya $H$, Shibuya N, Shimoda $M$ and Kubota K: Frequent alteration of the protein synthesis of enzymes for glucose metabolism in hepatocellular carcinomas. J Gastroenterol 49: 1324-1332, 2014.

27. Sekiba K, Otsuka M, Ohno M, Kishikawa T, Yamagami M, Suzuki T, Ishibashi R, Seimiya T, Tanaka E and Koike K: DHX9 regulates production of hepatitis B virus-derived circular RNA and viral protein levels. Oncotarget 9: 20953-20964, 2018.

28. Piao YF, He M, Shi Y and Tang TY: Relationship between microvessel density and telomerase activity in hepatocellular carcinoma. World J Gastroenterol 10: 2147-2149, 2004.

29. Siraj AK, Bu R, Iqbal K, Parvathareddy SK, Siraj N, Siraj S, Diaz MRF, Rala DR, Benito AD, Sabido MA, et al: Telomerase reverse transcriptase promoter mutations in cancers derived from multiple organ sites among middle eastern population. Genomics 112: 1746-1753, 2020.

30. Jin X, Beck S, Sohn YW, Kim JK, Kim SH, Yin J, Pian X, Kim SC, Choi YJ and Kim H: Human telomerase catalytic subunit (hTERT) suppresses p53-mediated anti-apoptotic response via induction of basic fibroblast growth factor. Exp Mol Med 42: 574-582, 2010.

31. Zhang Y, Toh L, Lau P and Wang X: Human telomerase reverse transcriptase (hTERT) is a novel target of the Wnt/beta-catenin pathway in human cancer. J Biol Chem 287: 32494-32511, 2012.

32. Ako S, Nouso K, Kinugasa $H$, Matsushita $H$, Terasawa $H$, Adachi T, Wada N, Takeuchi Y, Mandai M, Onishi $\mathrm{H}$, et al: Human telomerase reverse transcriptzse gene promotor mutation in serum of patients with hepatocellular carcinoma. Oncology 98: 311-317, 2020.

This work is licensed under a Creative Commons Attribution-NonCommercial-NoDerivatives 4.0 International (CC BY-NC-ND 4.0) License. 